\title{
Cellular and network mechanisms of electrographic seizures
}

\author{
Maxim Bazhenov, \\ The Salk Institute for Biological Studies, La Jolla, CA 92037 \\ Igor Timofeev, \\ Department of Anatomy and Physiology, School of Medicine, Laval University, The Centre de \\ Recherche Universite Laval Robert-Giffard, Québec, Canada G1J 2G3
}

Flavio Fröhlich, and

The Salk Institute for Biological Studies, La Jolla, CA 92037, Division of Biological Sciences, University of California San Diego, La Jolla CA 92093

\section{Terrence J. Sejnowski}

The Salk Institute for Biological Studies, La Jolla, CA 92037, Division of Biological Sciences, University of California San Diego, La Jolla CA 92093

\begin{abstract}
Epileptic seizures constitute a complex multiscale phenomenon that is characterized by synchronized hyperexcitation of neurons in neuronal networks. Recent progress in understanding pathological seizure dynamics provides crucial insights into underlying mechanisms and possible new avenues for the development of novel treatment modalities. Here we review some recent work that combines in vivo experiments and computational modeling to unravel the pathophysiology of seizures of cortical origin. We particularly focus on how activity-dependent changes in extracellular potassium concentration affects the intrinsic dynamics of neurons involved in cortical seizures characterized by spike/wave complexes and fast runs.
\end{abstract}

\section{Introduction}

It is widely accepted that the development of epileptiform activity can result from a shift in the balance between synaptic excitation and inhibition towards excitation (Dichter and Ayala 1987; Galarreta and Hestrin 1998; Nelson and Turrigiano 1998; Tasker and Dudek 1991). In fact, an easy way to elicit acute seizures experimentally is to block synaptic inhibition (Chagnac-Amitai and Connors 1989a; b; Gutnick et al. 1982; Matsumoto and Ajmone-Marsan 1964a; b; Prince 1978; Steriade et al. 1998). Accordingly, the traditional point of view is that the key intracellular correlate of epileptiform activity, the paroxysmal depolarizing shift (PDS), consists of a giant EPSP (Johnston and Brown 1981) enhanced by activation of voltageregulated intrinsic currents (de Curtis et al. 1999; Dichter and Ayala 1987; Prince and Connors 1984; Timofeev et al. 2004; Westbrook and Lothman 1983; Wong and Prince 1978). It was therefore a surprise when more recent evidence showed that synaptic inhibition remains functional in many forms of paroxysmal activities (Cohen et al. 2002; Davenport et al. 1990; Engel et al. 2003; Esclapez et al. 1997; Higashima 1988; Prince and Jacobs 1998; Timofeev et al. 2002b; Topolnik et al. 2003; Traub et al. 1996). Also, disruption of inhibitory function does not affect neocortical kindling (Denslow et al. 2001), which is associated with an increases

\footnotetext{
Publisher's Disclaimer: This is a PDF file of an unedited manuscript that has been accepted for publication. As a service to our customers we are providing this early version of the manuscript. The manuscript will undergo copyediting, typesetting, and review of the resulting proof before it is published in its final citable form. Please note that during the production process errors may be discovered which could affect the content, and all legal disclaimers that apply to the journal pertain.
} 
in synaptic strength that mediates recruitment of larger cortical areas (Teskey et al. 2002). Furthermore, the firing of fast-spiking inhibitory interneurons during cortically-generated seizures is much stronger than the activity of other types of cortical neurons (Timofeev et al. $2002 b$ ). Therefore, a decrease or even absence of synaptic inhibition in presence of synaptic excitation cannot serve as a general mechanism of cortical epileptic seizures.

Extracellular potassium concentration $\left[\mathrm{K}^{+}\right]_{\mathrm{o}}$ increases during neuronal activity. In presence of neuronal hyperexcitability, the $\left[\mathrm{K}^{+}\right]_{\mathrm{o}}$ apparatus fails to maintain $\left[\mathrm{K}^{+}\right]_{\mathrm{o}}$ homeostasis (Grafstein 1957, Somjen 2002, Frohlich 2007). The resulting increase in $\left[\mathrm{K}^{+}\right]_{\mathrm{o}}$ depolarizes the reversal potential of $\mathrm{K}^{+}$currents and can also affect the maximal conductances of some depolarizing currents such as the hyperpolarization-activated depolarizing current $\left(I_{h}\right)$ (Spain et al. 1987) and the persistent sodium current $\left(\mathrm{I}_{\mathrm{Na}(\mathrm{p})}\right)$ (Somjen and Muller 2000). Thus, the overall effect of an increase in $\left[\mathrm{K}^{+}\right]_{\mathrm{o}}$ is an upregulation of neuronal excitability. Indeed, periodic bursting was found in vitro after increasing $\left[\mathrm{K}^{+}\right]_{\mathrm{o}}$ (Jensen and Yaari 1997; Leschinger et al. 1993; Pan and Stringer 1997). Thus, changes in $\left[\mathrm{K}^{+}\right]_{\mathrm{o}}$ may play a critical role in seizure dynamics.

The complexity of the interaction dynamics between neuronal networks and ion concentrations during epileptiform activity requires a combined approach of experimental work and computational models. Here, we discuss recent modeling results regarding mechanisms of epileptic seizures in cortex. We first present an analysis of the network and cellular mechanisms of electrographic seizures in vivo. Then, we discuss the results from computational models that incorporate extracellular $\mathrm{K}^{+}$concentration dynamics based on experimental data. Our findings suggest that (1) changes in $\left[\mathrm{K}^{+}\right]_{\mathrm{o}}$ activate latent intrinsic burst dynamics that result in paroxysmal bursting and (2) the dynamic interaction between network activity and $\left[\mathrm{K}^{+}\right]_{\mathrm{o}}$ causes the emergence of a stable paroxysmal network state in the form of self-sustained oscillations. We conclude with specific predictions derived from our model and propose that molecular mechanisms responsible for $\left[\mathrm{K}^{+}\right]_{\mathrm{o}}$ regulation should be examined as novel targets for pharmacological intervention in patients suffering from epilepsy.

\section{Cortical origin of paroxysmal oscillations generated within the thalamocortical system}

The origin of electrical seizures that accompany various types of epilepsy is largely unknown, especially for cortically generated seizures. Recent experimental studies strongly implicate a neocortical origin of spike-wave (SW) electroencephalographic (EEG) complexes at $\sim 3 \mathrm{~Hz}$, as in petit-mal epilepsy and seizures with the EEG pattern of the Lennox-Gastaut syndrome (Pinault et al. 1998; Steriade 2003; Steriade et al. 1998; Steriade and Contreras 1998; Timofeev et al. 1998; Timofeev and Steriade 2004). The etiologies of cortically-generated seizures include cortical dysplasia, traumatic injury and other idiopathic/genetic forms (Stafstrom 2005). The cortical origin of these seizure types is supported by: (a) the presence of paroxysms in neuronal pools within the cortical depth, even without reflection at the cortical surface (Steriade 1974), and in isolated cortical slabs in vivo (Timofeev et al. 1998); (b) their induction by infusion of the $\mathrm{GABA}_{\mathrm{A}}$-receptor antagonist bicuculline in neocortex of ipsilaterally thalamectomized cats (Steriade and Contreras 1998); and (c) the absence of paroxysmal patterns after intrathalamic injections of bicuculline, which rather induce low-frequency, regularly recurring spindle sequences as previously described in ferret slices in vitro (Bal et al. 1995) and cat (Ajmone-Marsan and Ralston 1956; Steriade and Contreras 1998) or rat (Castro-Alamancos and Calcagnotto 1999) thalamus in vivo, (d) the vast majority of thalamocortical (TC) neurons is hyperpolarized and does not fire spikes during paroxysmal discharges recorded in corresponding cortical areas (Pinault et al. 1998; Steriade and Contreras 1995; Steriade and Timofeev 2001; Timofeev et al. 1998; Timofeev and Steriade 2004). 
As in the slow oscillation, cortical neurons are depolarized and fire spikes during the depthnegative (EEG spike) and are hyperpolarized during the depth-positive (EEG wave) components of SW. A typical example of a seizure that consists of both SW - poly-SW (PSW) complexes recurring with frequencies of $1-3 \mathrm{~Hz}$ and fast runs with oscillation frequencies of $8-14 \mathrm{~Hz}$ is shown in the Fig. 1. The seizure starts with SW-PSW discharges. The duration of PSW discharges increases progressively and the seizure displays a prolonged period of fast run. After the fast run the seizure transforms again to PSW complexes, the number of EEG spikes during these complexes decreases and the seizure terminates with SW discharges. Usually, SW-PSW complexes of electrographic seizures correspond to the clonic component of seizures, while fast runs correspond to the tonic component of seizures (Niedermeyer 2005a;b). Similar to spike-wave discharges, fast runs originate in neocortex. Since the frequency and the duration of fast runs are similar to spindles, it could be supposed that the runs of fast paroxysmal spikes share mechanisms with spindles and thus originate in the thalamus. However, the experimental evidence demonstrated that (a) during fast runs TC neurons display EPSPs that only rarely lead to the generation of action potentials (Timofeev et al. 1998) and not IPSP-mediated rebound $\mathrm{Ca}^{2+}$ spikes as during spindles, (b) the thalamic $\mathrm{Ca}^{2+}$ spike bursts precede the cortical depolarizing potentials during spindles, but, in the same cortex to TC neuronal pairs, the TC EPSPs occurring during fast runs follow the cortical neurons (see Fig. 11 in (Timofeev et al. 1998)). Also, runs of fast paroxysmal EEG spikes were found in isolated neocortical slabs (Timofeev et al. 1998). These observations confirm the cortical origin of fast runs.

\section{Cellular mechanisms mediating spike and wave discharges}

The EEG "spike" of SW complexes corresponds to the paroxysmal depolarizing shift (PDS) of the membrane voltage in intracellular recordings (reviewed in (McCormick and Contreras 2001; McNamara 1994; Traub et al. 1996)). Initially, PDSs have been regarded as giant EPSPs (Johnston and Brown 1981; 1984), enhanced by activation of voltage-gated intrinsic (highthreshold $\mathrm{Ca}^{2+}$ and persistent $\mathrm{Na}^{+}$) currents (de Curtis et al. 1999; Dichter and Ayala 1987; Timofeev et al. 2004; Wong and Prince 1978). Specifically, the EPSPs initiate the PDS by depolarizing the postsynaptic neurons to the level of activation of the persistent $\mathrm{Na}^{+}$current that maintains and enhances the achieved depolarization. This proposed contribution of the persistent $\mathrm{Na}^{+}$current to the generation of PDSs has been recently demonstrated by intracellular recordings from pairs of neurons, in which one of the neurons was recorded with a pipette containing QX-314, an intracellular blocker of voltage gated $\mathrm{Na}^{+}$currents. In all cells tested, the inclusion of QX-314 in the recording pipette caused a reduction of the maximal depolarization during the PDS (Fig. 2 B). Also, the PDSs increased their duration upon intracellular injection of steady depolarizing current (see Fig. 5 in (Timofeev et al. 2002b)). Intracellular recordings with the $\mathrm{Ca}^{2+}$ buffer BAPTA in the pipette indicate the role of $\mathrm{Ca}^{2+}$ dependent potassium current to the generation of hyperpolarizing potentials during seizures and indirectly support a role of $\mathrm{Ca}^{2+}$ influx via $\mathrm{Ca}^{2+}$ channels (Fig. $2 \mathrm{~A}$ ). Together, these findings suggest that high-threshold $\mathrm{Ca}^{2+}$ currents and the persistent $\mathrm{Na}^{+}$current could contribute to those depolarizations because these currents are activated at depolarized voltages.

In recent studies, inhibitory processes have been observed during different types of seizure activity (Esclapez et al. 1997; Prince and Jacobs 1998; Prince et al. 1997; Timofeev et al. 2002b; Traub et al. 1996). Recordings from human and rat slices (Cohen et al. 2002; FujiwaraTsukamoto et al. 2003) as well in vivo experiments in cats (Timofeev et al. 2002b) have demonstrated that PDSs contain an important inhibitory component. During the depolarizing components of seizures, the fast-spiking inhibitory interneurons fire at high frequencies (Timofeev et al. 2002b). The activation of postsynaptic $\mathrm{GABA}_{\mathrm{A}}$ receptors was substantial and caused the intracellular chloride concentration to increase (Timofeev et al. 2002b). This change in ion concentration gradient depolarized the reversal potential for $\mathrm{GABA}_{\mathrm{A}}$ inhibitory currents 
and thus decreased IPSP amplitudes or even reversed the polarity of IPSPs (Thompson and Gähwiler 1989). Also, prolonged high-frequency stimulation (Kaila et al. 1997; Taira et al. 1997) or spontaneous high-frequency firing of inhibitory interneurons (Timofeev et al.

$2002 b$ ) may induce a rapid $\mathrm{GABA}_{\mathrm{A}^{-}}$-mediated bicarbonate-dependent increase in the $[\mathrm{K}+]_{\mathrm{O}}$. An increase in $\left[\mathrm{K}^{+}\right]_{0}$ in mature neocortical pyramidal neurons would result in further increase in $\left[\mathrm{Cl}^{-}\right]_{\mathrm{i}}$ (DeFazio et al. 2000). The seizure-related depolarizing GABA responses are likely mediated via cation-chloride co-transporters (Payne et al. 2003).

Earlier hypotheses proposed that the EEG "wave" component reflects summated IPSPs that were ascribed to GABAergic processes triggered in cortical pyramidal neurons by local-circuit inhibitory cells (Giaretta et al. 1987; Pollen 1964). In computational models, the "wave" was similarly regarded as produced by GABA $_{B}$-mediated IPSPs (Destexhe 1998). However, during the EEG "waves" associated with neuronal hyperpolarization, the input resistance increases relative to the "spike" component (Matsumoto et al. 1969; Neckelmann et al. 2000; Timofeev et al. 2002b). These and similar results reported in a genetic rat model of absence epilepsy (Charpier et al. 1999; Crunelli and Leresche 2002; Staak and Pape 2001) and in cat in vivo (Timofeev et al. 2002b), contradict the idea of a role played by inhibitory receptors in the generation of hyperpolarizations associated with the EEG "wave" component of SW complexes. Furthermore, intracellular recordings with $\mathrm{Cl}^{-}$filled pipettes did not reveal chloride-mediated effects during 'wave' components of seizures (Timofeev et al. 2002b). As to the possibility that GABA $\mathrm{B}$-mediated IPSPs underlie the "wave" component of SW seizures, including QX-314 in the recording pipette to block the G-protein-coupled $\mathrm{GABA}_{\mathrm{B}}$-evoked $\mathrm{K}^{+}$current (Deisz et al. 1997; Jensen et al. 1993) did not significantly affect the hyperpolarization in our experiments (Fig. 2 B) (Timofeev et al. 2004; Timofeev and Steriade 2004). Together, these data suggested that GABA-mediated currents are not important for the hyperpolarizations that occur during these cortically-generated seizures.

Another group of mechanisms that can mediate hyperpolarization during SW complexes depends on $\mathrm{K}^{+}$currents (Halliwell 1986; Schwindt et al. 1988). In recordings with $\mathrm{Cs}^{+}$-filled pipettes to non-selectively block $\mathrm{K}^{+}$currents, pyramidal neurons displayed depolarizing potentials during the "wave" component of SW seizures (Timofeev et al. 2002b). This indicates a leading role played by $\mathrm{K}^{+}$currents in the generation of seizure-related hyperpolarizing potentials. A particularly important role is played by $\mathrm{I}_{\mathrm{K}(\mathrm{Ca})}$ because in recordings with pipettes filled with BAPTA the "wave"-related hyperpolarizations were reduced and the apparent input resistance increased (Timofeev et al. 2004; Timofeev and Steriade 2004). The second factor that may contribute to the "wave"-related hyperpolarization during cortically generated SW seizures is disfacilitation (Charpier et al. 1999; Neckelmann et al. 2000). Indeed, during the EEG "wave" component of SW seizures, cortical and TC neurons do not fire, thus creating conditions for disfacilitation. All these results indicate that the hyperpolarizations during SW seizure may be due to the combined effect of $\mathrm{K}^{+}$currents and disfacilitation.

What factors are implicated in the transition from neuronal hyperpolarization to depolarization during paroxysmal SW discharges? Intracellular recordings from glial cells and direct measurement of $\left[\mathrm{K}^{+}\right]_{\mathrm{o}}$ indicated an increase in $[\mathrm{K}+]_{\mathrm{o}}$ during paroxysmal activities (Amzica et al. 2002; Amzica and Steriade 2000; Moody et al. 1974; Timofeev et al. 2002a), leading to a positive shift in the reversal potential of $\mathrm{K}^{+}$-mediated currents, including $\mathrm{I}_{\mathrm{h}}$ (Spain et al. 1987). More than half of neocortical neurons display resonance within the frequency range of 1-3 Hz or higher, which is mediated by $I_{h}$ and enhanced by the persistent $\mathrm{Na}^{+}$current, $\mathrm{I}_{\mathrm{Na}}(\mathrm{p})$ (Hutcheon et al. 1996a; b; Hutcheon and Yarom 2000; Ulrich 2002). In our experiments, 20\% of neocortical neurons displayed depolarizing sags after application of hyperpolarizing current pulses, probably caused by activation of $\mathrm{I}_{\mathrm{h}}$. Also, models of isolated pyramidal neurons with $\mathrm{I}_{\mathrm{h}}$ included in their dendritic compartment showed that rebound depolarization was sufficient to generate single action potentials or spike-bursts (Timofeev et al. 2002a). The increased 
excitability of pyramidal neurons after the prolonged hyperpolarizations during the EEG "wave" component of SW complexes may contribute to the generation of the subsequent paroxysmal depolarization (Timofeev et al. 2002a; Timofeev and Steriade 2004). It is also possible that the $\mathrm{Ca}^{2+}$-mediated low-threshold current $\left(\mathrm{I}_{\mathrm{T}}\right)$, alone or in combination with $\mathrm{I}_{\mathrm{h}}$, contributes to the generation of the rebound overexcitation, as shown in cortical slices (de la Peña and Geijo-Barrientos 1996) and in computational studies (Destexhe et al. 2001).

However, the generation of $\mathrm{I}_{\mathrm{T}}$ in cortical neurons requires voltages much more hyperpolarized than those normally seen during spontaneously occurring network operations (Paré and Lang 1998). Thus, the next paroxysmal cycle likely originates from the excitation driven by $I_{h}$ in conjunction with synaptic inputs.

The summary diagram in Figure 3 tentatively indicates the different synaptic and intrinsic currents activated by neocortical neurons during paroxysmal activity. The PDS consists of (a) summated EPSPs and IPSPs; and (b) an intrinsic current, $\mathrm{I}_{\mathrm{Na}(\mathrm{p})}$, as revealed by diminished depolarization in recordings with QX-314 in the recording micropipette. The hyperpolarization related to the EEG depth-positive "wave" is a combination of $\mathrm{K}^{+}$currents (mainly $\mathrm{I}_{\mathrm{K}(\mathrm{Ca})}$ and $\mathrm{I}_{\text {leak }}$ ) and synaptic disfacilitation. Finally, the hyperpolarization-activated depolarizing sag, due to $\mathrm{I}_{\mathrm{h}}$, leads to a new paroxysmal cycle.

\section{Changes in the extracellular milieu and epileptogenesis}

Modulation of extracellular ionic concentrations has a profound impact on the excitability of neurons and neuronal networks. According to Grafstein's hypothesis (Herreras and Somjen 1993), $\mathrm{K}^{+}$released during intense neuronal firing may accumulate in the interstitial space, depolarize neurons and lead to spike inactivation. During seizures, the increase in $\left[\mathrm{K}^{+}\right]_{0}$ reaches $16 \mathrm{mM}$ in the case of 4-AP induced epileptiform discharges in hippocampus (Avoli et al. 1996) and 7-12 mM in case of spontaneous electrographic seizures in neocortex (Amzica et al. 2002; Moody et al. 1974; Prince et al. 1973). A recent computational study showed that $\mathrm{K}^{+}$-mediated increase in $\mathrm{I}_{\mathrm{h}}$ may lead to periodic bursting in a cortical network model (Timofeev et al. 2002a). It was shown that a combination of $I_{h}, I_{K(\mathrm{Ca})}$ and $I_{N a(p)}$ in pyramidal cells is sufficient to generate paroxysmal oscillations at a frequency of 2-3 Hz. These oscillations started when the $I_{K(l e a k)}$ and $I_{h}$ reversal potentials were depolarized and the maximal conductance for $I_{h}$ was increased to model the increased $\left[\mathrm{K}^{+}\right]_{\mathrm{o}}$ in paroxysmal foci (Timofeev et al. 2002a). A single PY cell with these properties was sufficient to mediate activity in an entire cortical network.

Cellular and network periodic bursting occurs in vitro after increasing $\left[\mathrm{K}^{+}\right]_{\mathrm{o}}$ (Jensen and Yaari 1997; Leschinger et al. 1993; Pan and Stringer 1997). Traumatic brain injury leading to loss of $\mathrm{K}^{+}$conductance in hippocampal glia can result in the failure of glial $\mathrm{K}^{+}$homeostasis and abnormal neuronal function including seizures (D'Ambrosio et al. 1999). The role of elevated $\left[\mathrm{K}^{+}\right]_{\mathrm{o}}$ in producing synchronized neuronal bursts through the shift of the $\mathrm{K}^{+}$reversal potential was previously studied in hippocampal slice models (Traub and Dingledine 1990). An initial computational model (Kager et al. 2000) exhibited periodic bursting after $\left[\mathrm{K}^{+}\right]_{\mathrm{o}}$ increase in a single model cell; however, the bursts occurred at a very low frequency (every 10-15 sec) which might be attributed to the lack of $\mathrm{I}_{\mathrm{K}(\mathrm{Ca})}$ in that model. An important role for the lowthreshold $\mathrm{Ca}^{2+}$ (T-type) current for generating spike-and-wave oscillations has also been recently suggested (Destexhe et al. 2001). In recordings from granule cells of the dentate gyrus in hippocampus at different levels of ionic concentrations in vitro, a simultaneous increase in $\left[\mathrm{K}^{+}\right]_{\mathrm{o}}$ and decrease in $\left[\mathrm{Ca}^{2+}\right]_{\mathrm{o}}$ caused cellular bursts to appear at $\mathrm{K}^{+} / \mathrm{Ca}^{2+}$ concentrations that were previously recorded in vivo before the onset of synchronized reverberatory seizure activity (Pan and Stringer 1997). Spontaneous nonsynaptic epileptiform activity was found in hippocampal slices after increasing neuronal excitability (by removing extracellular $\mathrm{Mg}^{2+}$ and increasing extracellular $\mathrm{K}^{+}$) in the presence of $\mathrm{Cd}^{2+}$, a nonselective $\mathrm{Ca}^{2+}$ channel antagonist, 
or veratridine, a persistent sodium conductance enhancer (Bikson et al. 2002). In recordings from rat hippocampal slices with high $\left[\mathrm{K}^{+}\right]_{\mathrm{o}}$, population bursts in CA1 were generated locally by intrinsically bursting pyramidal cells, which recruited and synchronized other neurons (Jensen and Yaari 1997).

Increases in $\left[\mathrm{K}^{+}\right]_{\mathrm{o}}$ unmasked a latent intrinsic burst mechanism that mediated $2-3 \mathrm{~Hz}$ oscillations in cortical neuron models that incorporate extracellular $\mathrm{K}^{+}$dynamics (Bazhenov et al. 2004). Such increases of $\left[\mathrm{K}^{+}\right]_{\mathrm{o}}$ can also lead to oscillations at the frequency of fast runs. An external stimulus (DC pulse of $10 \mathrm{sec}$ duration) applied to a single cortical pyramidal (PY) neuron induced a high-frequency spiking in this model cell (Fig. 4). A flow of $\mathrm{K}^{+}$ions to the extracellular milieu overpowered the effects of the $\mathrm{K}^{+}$pump and glial buffering, and led to $\left[\mathrm{K}^{+}\right]_{\mathrm{o}}$ increase (see insert in Fig. 4B). After stimulus termination, the neuron exhibited sustained periodic bursting in the $2-4 \mathrm{~Hz}$ frequency range. For each oscillation cycle, the slow membrane potential depolarization (due to combined effects of $\mathrm{I}_{\mathrm{h}}$ and high $\left[\mathrm{K}^{+}\right]_{\mathrm{o}}$ that depolarized the reversal potentials of all $\mathrm{K}^{+}$currents) activated the persistent sodium current and led to the onset of a new burst (see details in (Bazhenov et al. 2004)). Each burst started with a few spikes followed by spike inactivation and a depolarizing plateau that lasted 50-100 msec (see insert in Fig. 4A). Progressive increase of the intracellular $\mathrm{Ca}^{2+}$ concentration during the depolarized state increased activation of the $\mathrm{Ca}^{2+}$ dependent $\mathrm{K}^{+}$current until the neuron switched back to the hyperpolarized state. Deactivation of $\mathrm{I}_{\mathrm{K}(\mathrm{Ca})}$ determined the length of the hyperpolarized state and ultimately the frequency of slow bursting. Since $\mathrm{K}^{+}$reversal potentials remained below $-80 \mathrm{mV}$ in these simulations even when $\left[\mathrm{K}^{+}\right]_{\mathrm{o}}$ was elevated, the neuron stayed hyperpolarized below resting potential between bursts. During slow bursting, $\left[\mathrm{K}^{+}\right]_{\mathrm{O}}$ gradually decreased and 5-6 sec later, bursting was replaced by faster oscillations at 10-14 $\mathrm{Hz}$ range. Decrease of $\left[\mathrm{K}^{+}\right]_{\mathrm{o}}$ restored "normal" hyperpolarized $\mathrm{K}^{+}$reversal potentials. This increased the "hyperpolarizing force" such that the neuron did not stay "locked" in the depolarized state but repolarized back to the resting potential after one or few spikes. It also led to only minimal activation of the $\mathrm{Ca}^{2+}$ dependent $\mathrm{K}^{+}$current, so the next spike (or short burst of spikes) occurred with smaller delay. Therefore, the frequency of bursting increased and the neuron stayed at more depolarized level of membrane potential. Fast oscillations lasted 20-25 sec and eventually terminated when $\left[\mathrm{K}^{+}\right]_{\mathrm{O}}$ decreased below a level that was necessary to maintain spiking. Thus the change of the $\left[\mathrm{K}^{+}\right]_{\mathrm{o}}$ can account for transitions between slow and fast paroxysmal oscillations and silent state in the cortical neuron model.

To study effect of inhibitory feedback on the circuit dynamics, we included an inhibitory interneuron (IN) that receives synaptic excitation (AMPA-type) from the PY cell and in turn inhibits the PY cell (GABA $\mathrm{G}_{\mathrm{A}}$-type synapse). The strength of PY-IN synapse was adjusted so that IN remained silent during tonic firing of the PY neuron (Fig. 4B). When the PY neuron started to burst, the excitatory drive from PY to IN cell was sufficient to trigger periodic IN spiking. These inhibitory spikes reduced the duration of PY bursts and thus increased the oscillation frequency. In agreement with in vivo recordings (Timofeev et al. 2002b), the IN spiking stopped when the PY neuron switched from slow bursting to the tonic firing. Two main factors contributed to the absence of IN spiking during fast runs. First, steady-state depression of excitatory coupling between PY and IN neurons was stronger during fast runs since average frequency of PY spiking was higher due to the continuous firing. During slow bursting, shortterm depression was significantly reduced by the end of hyperpolarized (interburst) state. Second, during slow bursting the first few spikes at the burst onset occurred at a higher frequency than the spikes during fast run, therefore promoting EPSP summation in the IN.

\section{Effects of intrinsic conductances on $\mathrm{K}^{+-i n d u c e d ~ o s c i l l a t i o n s ~}$}

In agreement with in vivo results (see Fig. 3), high-threshold $\mathrm{Ca}^{2+}$ and persistent $\mathrm{Na}^{+}$currents were important in creating periodic bursting in our model of neocortical activity in moderately 
elevated $\left[\mathrm{K}^{+}\right]_{\mathrm{o}}$ (Fig. 5). After oscillations were induced by long DC stimulation, sufficiently high maximal conductances for $\mathrm{I}_{\mathrm{Na} \text { (p) }}$ and $\mathrm{I}_{\mathrm{Ca}}$ were required to maintain periodic bursting. On the $\mathrm{g}_{\mathrm{Ca}}\left(\mathrm{g}_{\mathrm{Na}}(\mathrm{p})\right.$ ) plane (see Fig. 5A, left) the region for bursting was bounded by two curves. Below the bottom curve, no oscillations were observed. Above the top curve, strong $\mathrm{I}_{\mathrm{Ca}}$ and/ or $\mathrm{I}_{\mathrm{Na}(\mathrm{p})}$ induced a transient "lock" of the membrane potential in a depolarized state (spike inactivation). All these regimes are illustrated in panel Fig. 5C, where the maximal change in $\left[\mathrm{Ca}^{2+}\right]_{\mathrm{i}}$ during a burst is plotted for a cell held at a constant elevated level of $\left[\mathrm{K}^{+}\right]_{\mathrm{o}}=5.5 \mathrm{mM}$. In particular, region $C$ corresponds to long bursts with spike inactivation. In region $D$, the membrane potential was permanently "locked" in a depolarized state, which occurred for high $\mathrm{g}_{\mathrm{Na}(\mathrm{p})}$ and relatively low $\mathrm{g}_{\mathrm{Ca}}$. The latter condition ensured weak $\mathrm{I}_{\mathrm{K}(\mathrm{Ca})}$ activation. Examples of different firing patterns are shown in Fig. 5B.

The value of the conductance that mediates $\mathrm{I}_{\mathrm{K}(\mathrm{Ca})}$ significantly affected both frequency and duration of the post-stimulus oscillations (Fig. 5A, right). When $\mathrm{g}_{\mathrm{K}(\mathrm{Ca})}$ was below about $2 \mathrm{mS} /$ $\mathrm{cm}^{2}$, only fast long-lasting oscillations were observed. For higher conductances $2-3 \mathrm{~Hz}$ periodic bursting was found. The frequency increased slightly for $\mathrm{g}_{\mathrm{K}(\mathrm{Ca})}$ above $5 \mathrm{mS} / \mathrm{cm}^{2}$, which was primary the result of reduced burst duration. Stronger $\mathrm{I}_{\mathrm{K}(\mathrm{Ca})}$ was more effective in terminating the depolarized plateau. As a result, less $\mathrm{Ca}^{2+}$ entered during the depolarized state and therefore the repolarization from the hyperpolarized state was also faster.

Among all the currents, $\mathrm{I}_{\mathrm{h}}$ was most effective in controlling the oscillation frequency. Decrease of $g_{h}$ reduced the frequency to about $1 \mathrm{~Hz}$ and very small values of $g_{h}$ eliminated bursting (Fig. 5D. left). This is consistent with the importance of $\mathrm{I}_{\mathrm{h}}$ in maintaining paroxysmal oscillations as proposed previously (Timofeev et al. 2002a). Increase of the maximal conductances for $\mathrm{I}_{\mathrm{Na}(\mathrm{p})}$ and $\mathrm{I}_{\mathrm{Km}}$ had opposing effects on the oscillation frequency (Fig. 5D, middle and right). Changing maximal conductance for $\mathrm{I}_{\mathrm{Ca}}$ had a relatively weak effect on the frequency, although the conductance value had to be above certain limit to maintain bursting. This limit depended

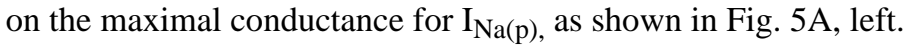

\section{Synchronization during fast runs and slow bursting}

We recently reported very low levels of both short- and long range synchronization during paroxysmal fast runs (Boucetta et al. 2008). To study synchrony of population oscillations during different oscillatory regimes, we used computer simulations of network models composed of 100 PY neurons and 25 INs. Without synaptic coupling, the model neurons fired independently because of random variability of the model parameters across neurons and different initial conditions. (Fig. 6A, top). Upon termination of a simulated DC stimulus, all neurons displayed slow bursting followed by fast spiking; in different neurons, these transitions between fast and slow oscillations occurred at different times. When excitatory/inhibitory coupling between neurons was included, slow paroxysmal bursting became synchronized across neurons (Fig. 6A, bottom). Fig. 6B shows the time-dependent cross-correlation between neighbor PY cells in the network; during slow paroxysmal oscillations PY neurons fired with minimal phase delays. Similar to the single neuron model (Fig. 4), progressive decrease in $\left[\mathrm{K}^{+}\right]_{\mathrm{o}}$ triggered a transition from slow to fast oscillations. In most cases, neighboring neurons displayed this transition nearly simultaneously; however we found a few large clusters with very different transition times (compare neurons \#1-50 and \#51-100 in Fig. 6A, bottom). We hypothesized that including long-range connections between PY neurons would increase the global synchrony of transitions between epochs of slow and fast oscillations. To test this hypothesis, we included random long-range connections between PY neurons and varied the probability of this long-range coupling $P$. Indeed, when $P>0.02-0.03$, the transition from slow bursting to fast run occurred almost simultaneously (within a $200 \mathrm{msec}$ time window). Including random long-range connections with such low probability did not produce any systematic effect on phase relations between closely-positioned neurons. 
In contrast to the slow bursting mode, the degree of synchrony between neurons (even in close proximity) was reduced during fast runs. Typically, neighboring neurons fired with a phase shift that was consistent for a few cycles of network oscillation thus suggesting local spike propagation. Different cell pairs displayed phase delays of different signs (propagation in different directions). Phase relations between neurons changed from in-phase to out-of-phase oscillations or vice versa either gradually (see, e.g., cross-correlation plot for PY35 and PY36 in Fig. 6B) or suddenly (see, e.g., cross-correlation plot for PY35 and PY38 in Fig. 6B). These modeling results suggest that during fast runs, local synaptic excitation controls phase relations between neighbor neurons but is not sufficient to arrange stable network synchronization. Furthermore, the synchronizing effect of feedback inhibition was absent during fast runs because of low spiking activity of inhibitory interneurons. Thus, random long-range connections may increase the synchrony of transitions between slow bursting and fast runs but do not affect the synchrony of oscillations on a cycle-to-cycle basis.

\section{Self-sustained oscillations mediated by extracellular $\mathrm{K}^{+}$dynamics}

In our modeling studies, the occurrence of oscillatory patterns displayed by cortical neurons (slow bursting or fast run) depended on the absolute level of $\left[\mathrm{K}^{+}\right]_{\mathrm{o}}$ (Bazhenov et al. 2004; Frohlich et al. 2006). In the model of an isolated cortical neuron, fast runs were the only stable firing pattern in presence of moderately elevated levels of $\left[\mathrm{K}^{+}\right]_{\mathrm{o}}\left(\left[\mathrm{K}^{+}\right]_{\mathrm{o}}<\left[\mathrm{K}^{+}\right]_{\mathrm{o}}{ }^{\mathrm{cr} 1} \cong 5.75 \mathrm{mM}\right)$. For higher $\left[\mathrm{K}^{+}\right]_{\mathrm{o}}$ levels $\left(\left[\mathrm{K}^{+}\right]_{\mathrm{o}}>\left[\mathrm{K}^{+}\right]_{\mathrm{o}}{ }^{\mathrm{cr} 2} \cong 6.4 \mathrm{mM}\right)$, slow bursting was the only stable firing pattern. Importantly, for an intermediate range of $\left[\mathrm{K}^{+}\right]_{\mathrm{o}}$, these two different oscillatory states co-exist $\left(\left[\mathrm{K}^{+}\right]_{\mathrm{o}}{ }^{\mathrm{cr} 1}<\left[\mathrm{K}^{+}\right]_{\mathrm{o}}<\left[\mathrm{K}^{+}\right]_{\mathrm{o}}{ }^{\mathrm{cr} 2}\right)$ (Frohlich and Bazhenov 2006; Frohlich et al. 2006) - a phenomenon called bistability. In this range of $\left[\mathrm{K}^{+}\right]_{\mathrm{o}}$, the system could display either tonic spiking or slow bursting depending on the initial state of the cell. In the single cell model, however, this bistability does not play a significant role because of the progressive monotonic $\left[\mathrm{K}^{+}\right]_{\mathrm{o}}$ decay. In the network model, however, the same bistability leads to self-sustained oscillations shaped into an alternating sequence of slow bursting and fast run epochs, each lasting several seconds (Fig. 7A). Due to the lateral excitatory connections, the frequency of fast runs was higher in the network model compared to the isolated neuron. Thus, during fast runs, the activity-dependent $\mathrm{K}^{+}$efflux overwhelmed the $\left[\mathrm{K}^{+}\right]_{\mathrm{o}}$ regulation mechanism and therefore the level of $\left[\mathrm{K}^{+}\right]_{\mathrm{o}}$ progressively increased. This further increased the network excitability (positive feedback) until the network switched to the slow bursting mode at $\left[\mathrm{K}^{+}\right]_{\mathrm{o}}{ }^{\mathrm{cr} 2}$ (Fig. 7B). During slow bursting, the average network activity was much lower since it was dominated by relatively long intervals of silence between bursts. Due to the relatively weak $\mathrm{K}^{+}$efflux during slow bursting, the $\left[\mathrm{K}^{+}\right]_{\mathrm{o}}$ regulation apparatus was sufficiently strong to clear excess $\left[\mathrm{K}^{+}\right]_{0}$. As a result, $\left[\mathrm{K}^{+}\right]_{0}$ decreased until it reached the point $\left(\left[\mathrm{K}^{+}\right]_{0}{ }^{\mathrm{crl}}\right)$ where the network could not sustain bursting anymore and the network switched back to fast run, thus starting a new cycle of slow state transitions between fast run and slow bursting. We also found that the persistence of this transient dynamics depended on the balance between synaptic inhibition and excitation in the network (Frohlich and Bazhenov 2006; Frohlich et al. 2006). An activity-dependent increase in intracellular chloride concentration mediated by inhibitory synaptic currents caused a depolarizing shift in the reversal potential of chloride leading to a decrease in inhibition. The resulting overall shift in the balance between synaptic excitation and inhibition favored the slow bursting state during which $\left[\mathrm{K}^{+}\right]_{0}$ decreased to eventually return to baseline causing termination of the oscillatory activity (Fig. 8) (Frohlich et al. 2007). Our model shows that the hysteresis between slow and fast oscillations in a single neuron could serve as the basis for both the maintenance and termination of slow bursting and fast runs seen in cat neocortex in vivo. 


\section{Conclusion}

Epileptic seizures are commonly considered unstable runaway dynamics of neuronal networks. Specifically, it has been suggested that positive feedback interaction between extracellular potassium and neural activity mediates cortical seizures. In a series of studies, reviewed here, we showed that epileptic seizures may represent a stable (or quasi-stable) cortical state caused by extracellular potassium concentration dynamics. This pathological state consisted of alternating epochs of tonic firing and bursting and coexisted with another attractor representing normal (healthy) cortical dynamics. This novel and surprising finding is in contrast with the currently held belief that epileptic seizures represent runaway network instabilities.

The basin of attraction of the "pathological" brain state depends on the variety of factors including intrinsic and synaptic conductances, synaptic connectivity patterns and may vary between healthy and epileptic brains. An increase in the size of this basin in patients suffering from epilepsy would reduce the threshold for transitions from the physiological to the pathological state. It may also affect an average time the brain spends in the pathological state (i.e. duration of seizures). The proposed model may explain the relatively random occurrence of most seizures. In the epileptic brain, internal fluctuations or external inputs would more easily drive the network into the basin of attraction of the seizure state due to its increased size. In contrast, such transitions may never occur in the non-epileptic brain.

Current antiepileptic drugs mainly either enhance $\mathrm{GABA}_{\mathrm{A}}$ inhibition or decrease sodium currents. Approximately one-third of patients with symptomatic localization-related epilepsy syndromes (e.g., trauma) are refractory to available antiepileptic medications (Kwan and Brodie 2000). In these patients, therapeutical agents that stabilize $\left[\mathrm{K}^{+}\right]_{\mathrm{o}}$ at physiological levels could block the epileptic activity. A promising target for such therapeutics may be the astroglial KIR channels, which play a role in the $\mathrm{K}^{+}$reuptake and spatial buffering (Newman 1986; 1993). The successful development of such treatment modalities could eventually reduce the number of patients suffering from drug-resistant epilepsy.

\section{References}

Ajmone-Marsan C, Ralston B. Thalamic control of certain normal and abnormal cortical rhythms. Electroencephalography and clinical neurophysiology 1956;8:559-582. [PubMed: 13375497]

Amzica F, Massimini M, Manfridi A. Spatial buffering during slow and paroxysmal sleep oscillations in cortical networks of glial cells in vivo. J Neurosci 2002;22:1042-1053. [PubMed: 11826133]

Amzica F, Steriade M. Neuronal and glial membrane potentials during sleep and paroxysmal oscillations in the neocortex. J Neurosci 2000;20:6648-6665. [PubMed: 10964970]

Avoli M, Barbarosie M, Lucke A, Nagao T, Lopantsev V, Kohling R. Synchronous GABA-mediated potentials and epileptiform discharges in the rat limbic system in vitro. J Neurosci 1996;16:39123924. [PubMed: 8656285]

Bal T, von Krosigk M, McCormick DA. Synaptic and membrane mechanisms underlying synchronized oscillations in the ferret lateral geniculate nucleus in vitro. Journal of Physiology 1995;483:641-663. [PubMed: 7776249]

Bazhenov M, Timofeev I, Steriade M, Sejnowski TJ. Potassium model for slow (2-3 Hz) in vivo neocortical paroxysmal oscillations. Journal of neurophysiology 2004;92:1116-1132. [PubMed: 15056684]

Bikson M, Baraban SC, Durand DM. Conditions sufficient for nonsynaptic epileptogenesis in the CA1 region of hippocampal slices. Journal of neurophysiology 2002;87:62-71. [PubMed: 11784730]

Boucetta S, Chauvette S, Bazhenov M, Timofeev I. Focal generation of paroxysmal fast runs during electrographic seizures. Epilepsia. 2008in press

Castro-Alamancos MA, Calcagnotto ME. Presynaptic long-term potentiation in corticothalamic synapses. J Neurosci 1999;19:9090-9097. [PubMed: 10516326] 
Chagnac-Amitai Y, Connors BW. Horizontal spread of synchronized activity in neocortex and its control by GABA-mediated inhibition. Journal of neurophysiology 1989a;61:747-758. [PubMed: 2542471]

Chagnac-Amitai Y, Connors BW. Synchronized excitation and inhibition driven by intrinsically bursting neurons in neocortex. Journal of neurophysiology 1989b;62:1149-1162. [PubMed: 2585046]

Charpier S, Leresche N, Deniau JM, Mahon S, Hughes SW, Crunelli V. On the putative contribution of $\mathrm{GABA}(\mathrm{B})$ receptors to the electrical events occurring during spontaneous spike and wave discharges. Neuropharmacology 1999;38:1699-1706. [PubMed: 10587086]

Cohen I, Navarro V, Clemenceau S, Baulac M, Miles R. On the origin of interictal activity in human temporal lobe epilepsy in vitro. Science (New York, NY 2002;298:1418-1421.

Crunelli V, Leresche N. Childhood absence epilepsy: genes, channels, neurons and networks. Nat Rev Neurosci 2002;3:371-382. [PubMed: 11988776]

D'Ambrosio R, Maris DO, Grady MS, Winn HR, Janigro D. Impaired K(+) homeostasis and altered electrophysiological properties of post-traumatic hippocampal glia. J Neurosci 1999;19:8152-8162. [PubMed: 10479715]

Davenport CJ, Brown WJ, Babb TL. GABAergic neurons are spared after intrahippocampal kainate in the rat. Epilepsy Res 1990;5:28-42. [PubMed: 2303020]

de Curtis M, Radici C, Forti M. Cellular mechanisms underlying spontaneous interictal spikes in an acute model of focal cortical epileptogenesis. Neuroscience 1999;88:107-117. [PubMed: 10051193]

de la Peña E, Geijo-Barrientos E. Laminar localization, morphology, and physiological properties of pyramidal neurons that have the low-threshold calcium current in the guinea-pig medial frontal cortex. J Neuroscience 1996;16:5301-5311.

DeFazio RA, Keros S, Quick MW, Hablitz JJ. Potassium-coupled chloride cotransport controls intracellular chloride in rat neocortical pyramidal neurons. J Neurosci 2000;20:8069-8076. [PubMed: 11050128]

Deisz RA, Billard JM, Zieglgansberger W. Presynaptic and postsynaptic GABAB receptors of neocortical neurons of the rat in vitro: differences in pharmacology and ionic mechanisms. Synapse (New York, NY 1997;25:62-72.

Denslow MJ, Eid T, Du F, Schwarcz R, Lothman EW, Steward O. Disruption of inhibition in area CA1 of the hippocampus in a rat model of temporal lobe epilepsy. Journal of neurophysiology 2001;86:2231-2245. [PubMed: 11698514]

Destexhe A. Spike-and-wave oscillations based on the properties of GABAB receptors. J Neurosci 1998;18:9099-9111. [PubMed: 9787013]

Destexhe A, Contreras D, Steriade M. LTS cells in cerebral cortex and their role in generating spike-andwave oscillations. Neurocomputing 2001;38-40:555-563.

Dichter MA, Ayala GF. Cellular mechanisms of epilepsy: a status report. Science (New York, NY 1987;237:157-164.

Engel J Jr, Wilson C, Bragin A. Advances in understanding the process of epileptogenesis based on patient material: what can the patient tell us? Epilepsia 2003;44(Suppl 12):60-71. [PubMed: 14641562]

Esclapez M, Hirsch JC, Khazipov R, Ben-AriI Y, Bernard C. Operative GABAergic inhibition in hippocampal CA1 pyramidal neurons in experimental epilepsy. Proc Natl Acad Sci U S A 1997;94:12151-12156. [PubMed: 9342378]

Frohlich F, Bazhenov M. Coexistence of tonic firing and bursting in cortical neurons. Phys Rev E Stat Nonlin Soft Matter Phys 2006;74:031922. [PubMed: 17025682]

Frohlich F, Bazhenov M, Timofeev I, Sejnowski TJ. Maintenance and termination of neocortical oscillations by dynamic modulation of intrinsic and synaptic excitability. Thalamus \& Related Systems. 200710.1017/S1472928807000155

Frohlich F, Bazhenov M, Timofeev I, Steriade M, Sejnowski TJ. Slow state transitions of sustained neural oscillations by activity-dependent modulation of intrinsic excitability. J Neurosci 2006;26:61536162. [PubMed: 16763023]

Fujiwara-Tsukamoto Y, Isomura Y, Nambu A, Takada M. Excitatory gaba input directly drives seizurelike rhythmic synchronization in mature hippocampal CA1 pyramidal cells. Neuroscience 2003;119:265-275. [PubMed: 12763087]

Galarreta M, Hestrin S. Frequency-dependent synaptic depression and the balance of excitation and inhibition in the neocortex. Nat Neurosci 1998;1:587-594. [PubMed: 10196566] 
Giaretta D, Avoli M, Gloor P. Intracellular recordings in pericruciate neurons during spike and wave discharges of feline generalized penicillin epilepsy. Brain research 1987;405:68-79. [PubMed: 3032351]

Gutnick MJ, Connors BW, Prince DA. Mechanisms of neocortical epileptogenesis in vitro. Journal of neurophysiology 1982;48:1321-1335. [PubMed: 7153795]

Halliwell JV. M-current in human neocortical neurones. Neuroscience letters 1986;67:1-6. [PubMed: 2425294]

Herreras O, Somjen GG. Analysis of potential shifts associated with recurrent spreading depression and prolonged unstable spreading depression induced by microdialysis of elevated $\mathrm{K}+$ in hippocampus of anesthetized rats. Brain research 1993;610:283-294. [PubMed: 8319090]

Higashima M. Inhibitory processes in development of seizure activity in hippocampal slices. Exp Brain Res 1988;72:37-44. [PubMed: 3169194]

Hutcheon B, Miura RM, Puil E. Models of subthreshold membrane resonance in neocortical neurons. Journal of neurophysiology 1996a;76:698-714. [PubMed: 8871192]

Hutcheon B, Miura RM, Puil E. Subthreshold membrane resonance in neocortical neurons. Journal of neurophysiology 1996b;76:683-697. [PubMed: 8871191]

Hutcheon B, Yarom Y. Resonance, oscillation and the intrinsic frequency preferences of neurons. Trends Neurosci 2000;23:216-222. [PubMed: 10782127]

Jensen MS, Cherubini E, Yaari Y. Opponent effects of potassium on GABAa-mediated postsynaptic inhibition in the rat hippocampus. Journal of neurophysiology 1993;69:764-771. [PubMed: 8385194]

Jensen MS, Yaari Y. Role of intrinsic burst firing, potassium accumulation, and electrical coupling in the elevated potassium model of hippocampal epilepsy. Journal of neurophysiology 1997;77:12241233. [PubMed: 9084592]

Johnston D, Brown TH. Giant synaptic potential hypothesis for epileptiform activity. Science (New York, NY 1981;211:294-297.

Johnston D, Brown TH. The synaptic nature of the paroxysmal depolarizing shift in hippocampal neurons. Ann Neurol 1984;16:S65-71. [PubMed: 6095744]

Kager H, Wadman WJ, Somjen GG. Simulated seizures and spreading depression in a neuron model incorporating interstitial space and ion concentrations. Journal of neurophysiology 2000;84:495-512. [PubMed: 10899222]

Kaila K, Lamsa K, Smirnov S, Taira T, Voipio J. Long-lasting GABA-mediated depolarization evoked by high-frequency stimulation in pyramidal neurons of rat hippocampal slice is attributable to a network-driven, bicarbonate-dependent K+ transient. J Neurosci 1997;17:7662-7672. [PubMed: 9315888]

Kwan P, Brodie MJ. Early identification of refractory epilepsy. N Engl J Med 2000;342:314-319. [PubMed: 10660394]

Leschinger A, Stabel J, Igelmund P, Heinemann U. Pharmacological and electrographic properties of epileptiform activity induced by elevated $\mathrm{K}+$ and lowered $\mathrm{Ca} 2+$ and $\mathrm{Mg} 2+$ concentration in rat hippocampal slices. Exp Brain Res 1993;96:230-240. [PubMed: 7903641]

Matsumoto H, Ajmone-Marsan C. Cortical cellular phenomena in experimental epilepsy: ictal manifestations. Experimental Neurology 1964a;9:305-326. [PubMed: 14142796]

Matsumoto H, Ajmone-Marsan C. Cortical cellular phenomena in experimental epilepsy: interictal manifestations. Experimental Neurology 1964b;9:286-304. [PubMed: 14145629]

Matsumoto H, Ayala GF, Gumnit RJ. Effects of intracellularly injected currents on the PDS and the hyperpolarizing after-potential in neurons within an epileptic focus. Electroencephalography and clinical neurophysiology 1969;26:120. [PubMed: 4183218]

McCormick DA, Contreras D. On the cellular and network bases of epileptic seizures. Annu Rev Physiol 2001;63:815-846. [PubMed: 11181977]

McNamara JO. Cellular and molecular basis of epilepsy. J Neurosci 1994;14:3413-3425. [PubMed: 8207463]

Moody WJ, Futamachi KJ, Prince DA. Extracellular potassium activity during epileptogenesis. Exp Neurol 1974;:42:248-263. [PubMed: 4824976] 
Neckelmann D, Amzica F, Steriade M. Changes in neuronal conductance during different components of cortically generated spike-wave seizures. Neuroscience 2000;96:475-485. [PubMed: 10717428]

Nelson SB, Turrigiano GG. Synaptic depression: a key player in the cortical balancing act. Nat Neurosci 1998;1:539-541. [PubMed: 10196556]

Newman EA. High potassium conductance in astrocyte endfeet. Science (New York, NY 1986;233:453454.

Newman EA. Inward-rectifying potassium channels in retinal glial (Muller) cells. J Neurosci 1993;13:3333-3345. [PubMed: 8340811]

Niedermeyer, E. Abnormal EEG patterns: epileptic and paroxysmal. In: Niedermeyer, E.; Lopes de Silva, F., editors. Electroencephalography: Basic Principles, Clinical Applications, and Related Fields. Philadelphia: Lippincott Williams \& Wilkins; 2005a. p. 255-280.

Niedermeyer, E. Epileptic seizure disorders. In: Niedermeyer, E.; Lopes de Silva, F., editors. Electroencephalography: Basic Principles, Clinical Applications, and Related Fields. Philadelphia: Lippincott Williams \& Wilkins; 2005b. p. 505-620.

Pan E, Stringer JL. Role of potassium and calcium in the generation of cellular bursts in the dentate gyrus. Journal of neurophysiology 1997;77:2293-2299. [PubMed: 9163358]

Paré D, Lang EJ. Calcium electrogenesis in neocortical pyramidal neurons in vivo. Eur J Neurosci 1998;10:3164-3170. [PubMed: 9786210]

Payne JA, Rivera C, Voipio J, Kaila K. Cation-chloride co-transporters in neuronal communication, development and trauma. Trends Neurosci 2003;26:199-206. [PubMed: 12689771]

Pinault D, Leresche N, Charpier S, Deniau JM, Marescaux C, Vergnes M, Crunelli V. Intracellular recordings in thalamic neurones during spontaneous spike and wave discharges in rats with absence epilepsy. J Physiol 1998;509:449-456. [PubMed: 9575294]

Pollen DA. Intracellular studies of cortical neurons during thalamic induced wave and spike. Electroencephalography and clinical neurophysiology 1964;17:398-404. [PubMed: 14236822]

Prince DA. Neurophysiology of epilepsy. Annu Rev Neurosci 1978;1:395-415. [PubMed: 386906]

Prince DA, Connors BW. Mechanisms of epileptogenesis in cortical structures. Ann Neurol 1984;16:S59-64. [PubMed: 6095743]

Prince DA, Jacobs K. Inhibitory function in two models of chronic epileptogenesis. Epilepsy Res 1998;32:83-92. [PubMed: 9761311]

Prince DA, Jacobs KM, Salin PA, Hoffman S, Parada I. Chronic focal neocortical epileptogenesis: does disinhibition play a role? Can J Physiol Pharmacol 1997;75:500-507. [PubMed: 9250384]

Prince DA, Lux HD, Neher E. Measurement of extracellular potassium activity in cat cortex. Brain research 1973;50:489-495. [PubMed: 4705519]

Schwindt PC, Spain WJ, Foehring RC, Stafstrom CE, Chubb MC, Crill WE. Multiple potassium conductances and their functions in neurons from cat sensorimotor cortex in vitro. Journal of neurophysiology 1988;59:424-449. [PubMed: 3351569]

Somjen GG, Muller M. Potassium-induced enhancement of persistent inward current in hippocampal neurons in isolation and in tissue slices. Brain research 2000;885:102-110. [PubMed: 11121535]

Spain WJ, Schwindt PC, Crill WE. Anomalous rectification in neurons from cat sensorimotor cortex. Journal of neurophysiology 1987;57:1555-1576. [PubMed: 3585479]

Staak R, Pape HC. Contribution of GABA(A) and GABA(B) receptors to thalamic neuronal activity during spontaneous absence seizures in rats. J Neurosci 2001;21:1378-1384. [PubMed: 11160409]

Stafstrom CE. Neurons do the wave (and the spike!) during neocortical seizures. Epilepsy currents/ American Epilepsy Society 2005;5:69-71. [PubMed: 16059440]

Steriade M. Interneuronal epileptic discharges related to spike-and-wave cortical seizures in behaving monkeys. Electroencephalography and clinical neurophysiology 1974;37:247-263. [PubMed: 4136833]

Steriade, M. Neuronal substrates of sleep and epilepsy. Cambridge (UK): Cambridge Univ. Press; 2003.

Steriade M, Amzica F, Neckelmann D, Timofeev I. Spike-wave complexes and fast components of cortically generated seizures. II. Extra- and intracellular patterns. Journal of neurophysiology 1998;80:1456-1479. [PubMed: 9744952] 
Steriade M, Contreras D. Relations between cortical and thalamic cellular events during transition from sleep patterns to paroxysmal activity. J Neurosci 1995;15:623-642. [PubMed: 7823168]

Steriade M, Contreras D. Spike-wave complexes and fast components of cortically generated seizures. I. Role of neocortex and thalamus. Journal of neurophysiology 1998;80:1439-1455. [PubMed: 9744951]

Steriade M, Timofeev I. Corticothalamic operations through prevalent inhibition of thalamocortical neurons. Thalamus and related systems 2001;1:225-236.

Taira T, Lamska K, Kaila K. Posttetanic excitation mediated by GABAa receptors in rat CA1 pyramidal neurons. Journal of neurophysiology 1997;77:2213-2218. [PubMed: 9114269]

Tasker GJ, Dudek FE. Electrophysiology of GABA-mediated synaptic transmission and possible roles in epilepsy. Neurochemical Research 1991;16:251-262. [PubMed: 1664056]

Teskey GC, Monfils MH, VandenBerg PM, Kleim JA. Motor map expansion following repeated cortical and limbic seizures is related to synaptic potentiation. Cereb Cortex 2002;12:98-105. [PubMed: 11734536]

Thompson SM, Gähwiler BH. Activity-dependent disinhibition. I. Repetitive stimulation reduces IPSP driving force and conductance in the hippocampus in vitro. Journal of neurophysiology 1989;61:501511. [PubMed: 2709096]

Timofeev I, Bazhenov M, Sejnowski T, Steriade M. Cortical hyperpolarization-activated depolarizing current takes part in the generation of focal paroxysmal activities. Proc Natl Acad Sci U S A 2002a; 99:9533-9537. [PubMed: 12089324]

Timofeev I, Grenier F, Steriade M. Contribution of intrinsic cellular factors in the generation of cortically generated electrographic seizures. J Neurophys 2004;92:1133-1143.

Timofeev I, Grenier F, Steriade M. The role of chloride-dependent inhibition and the activity of fastspiking neurons during cortical spike-wave seizures. Neurosci 2002b;114:1115-1132.

Timofeev I, Grenier F, Steriade M. Spike-wave complexes and fast components of cortically generated seizures. IV. Paroxysmal fast runs in cortical and thalamic neurons. Journal of neurophysiology 1998;80:1495-1513. [PubMed: 9744954]

Timofeev I, Steriade M. Neocortical seizures: initiation, development and cessation. Neuroscience 2004;123:299-336. [PubMed: 14698741]

Topolnik L, Steriade M, Timofeev I. Hyperexcitability of intact neurons underlies acute development of trauma-related electrographic seizures in cats in vivo. Eur J Neurosci 2003;18:486-496. [PubMed: 12911745]

Traub RD, Borck C, Colling SB, Jefferys JG. On the structure of ictal events in vitro. Epilepsia 1996;37:879-891. [PubMed: 8814102]

Traub RD, Dingledine R. Model of synchronized epileptiform bursts induced by high potassium in CA3 region of rat hippocampal slice. Role of spontaneous EPSPs in initiation. Journal of neurophysiology 1990;64:1009-1018. [PubMed: 2230914]

Ulrich D. Dendritic resonance in rat neocortical pyramidal cells. Journal of neurophysiology 2002;87:2753-2759. [PubMed: 12037177]

Westbrook GL, Lothman EW. Cellular and synaptic basis of kainic acid-induced hippocampal epileptiform activity. Brain research 1983;273:97-109. [PubMed: 6311348]

Wong RK, Prince DA. Participation of calcium spikes during intrinsic burst firing in hippocampal neurons. Brain research 1978;159:385-390. [PubMed: 728808] 


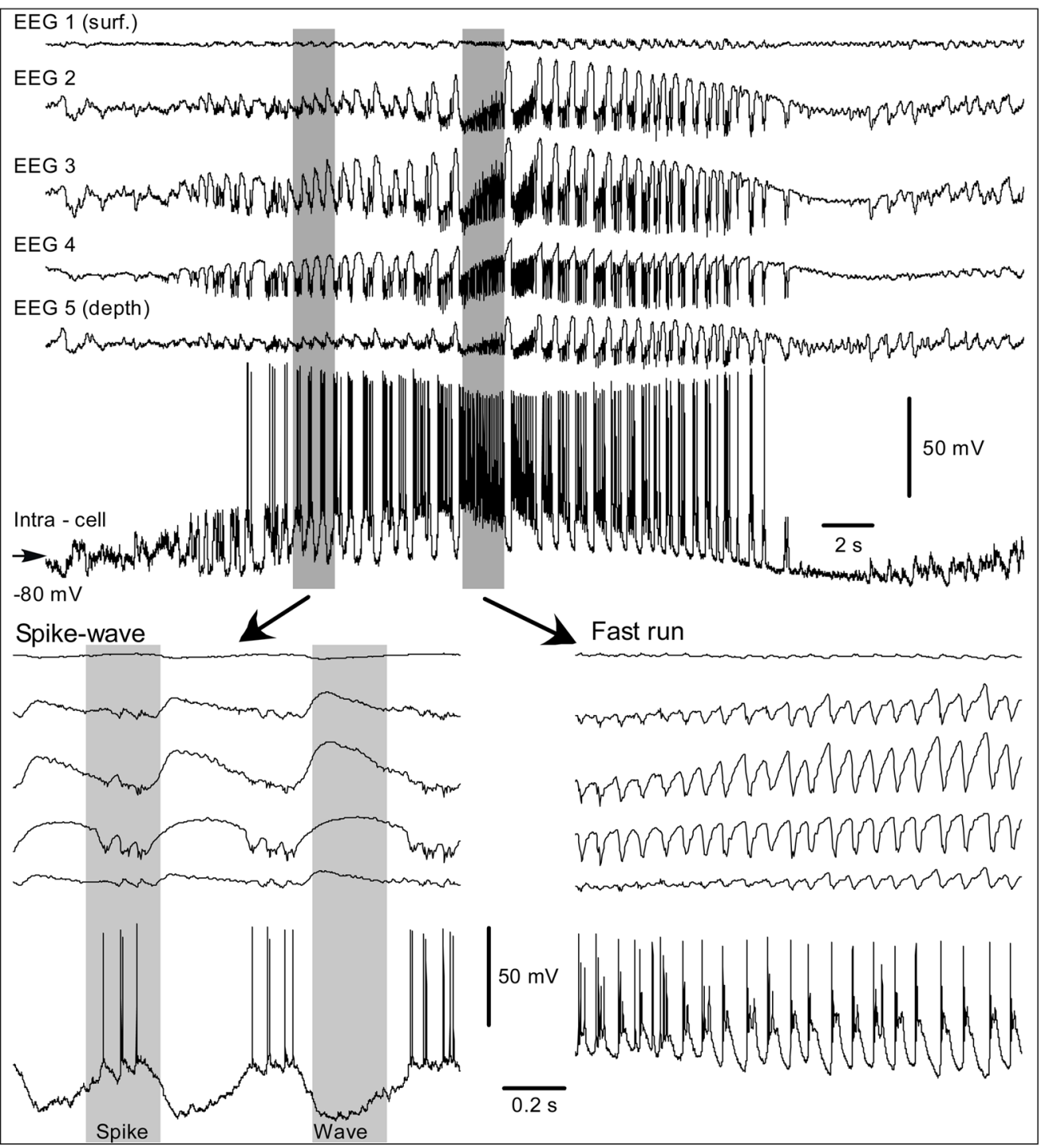

Fig. 1. Field potential and intracellular features of an idiopathic electographic seizure recorded from cortical area 5 of cat anesthetized with ketamine-xylazine Upper panel, five upper traces are the local field potentials recorded with an array of electrodes from cortical surface and different cortical depths. The distance between electrodes in the array was $\sim 0.4 \mathrm{~mm}$. Lower trace, intracellular recording from cortical regular-spiking neuron located at $1 \mathrm{~mm}$ depth and $\sim 0.5 \mathrm{~mm}$ lateral to the array. A period of spike-wave discharges and fast runs is expanded in the lower panels as indicated. In the left lower panel the EEG-spike and the EEG-wave components are marked by grey rectangles. 


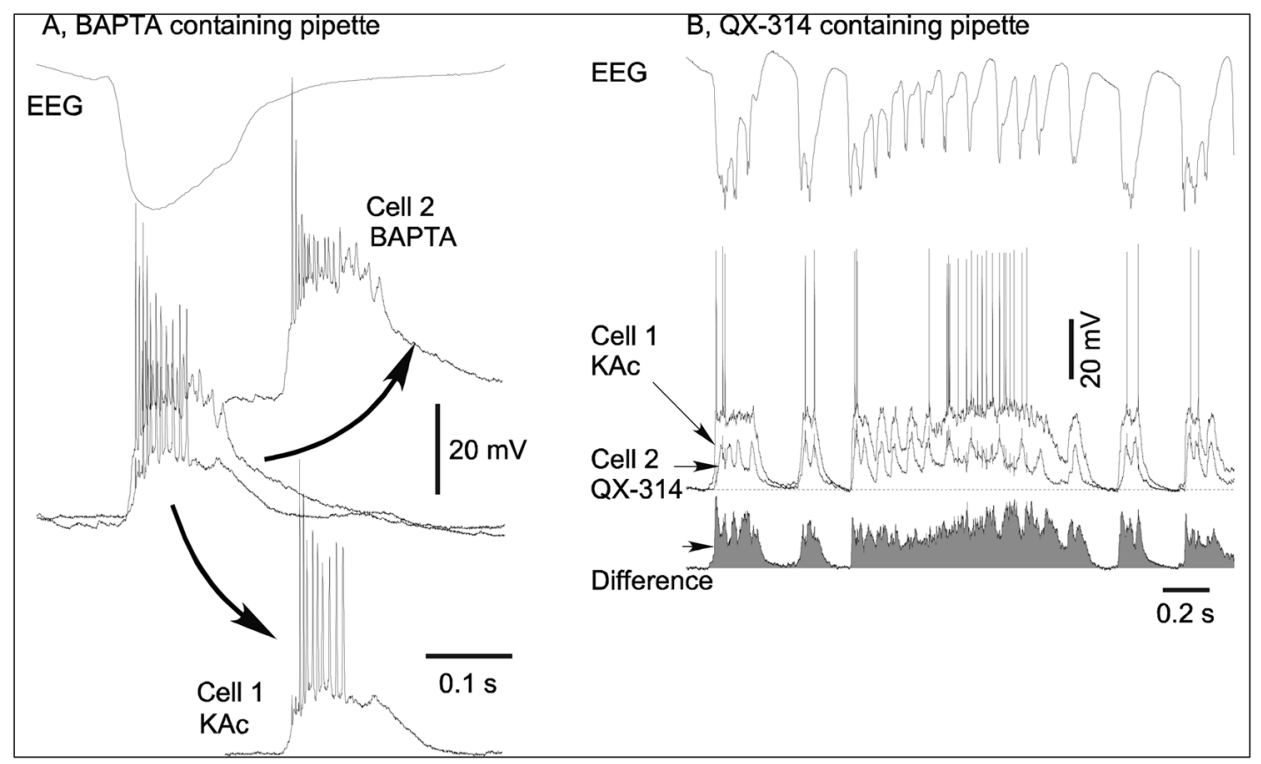

Fig. 2. Role of $\mathrm{Ca}^{2+}$-activated and persistent $\mathrm{Na}^{+}$currents in the generation of paroxysmal depolarizing shifts

(A) EEG and dual intracellular recordings during a paroxysmal depolarizing shift. Intracellular recording with BAPTA field pipette reveals much larger depolarization during the paroxysmal depolarizing shift as compared to control recording with $\mathrm{K}^{+}$acetate filled pipette. (B) EEG and dual intracellular recordings during a fragment of a seizure. One of the pipettes contained QX-314. The neuron recorded with this pipette revealed much smaller depolarization during paroxysmal activities as shown in the trace "difference". (Modified from (Timofeev et al. 2004)). 


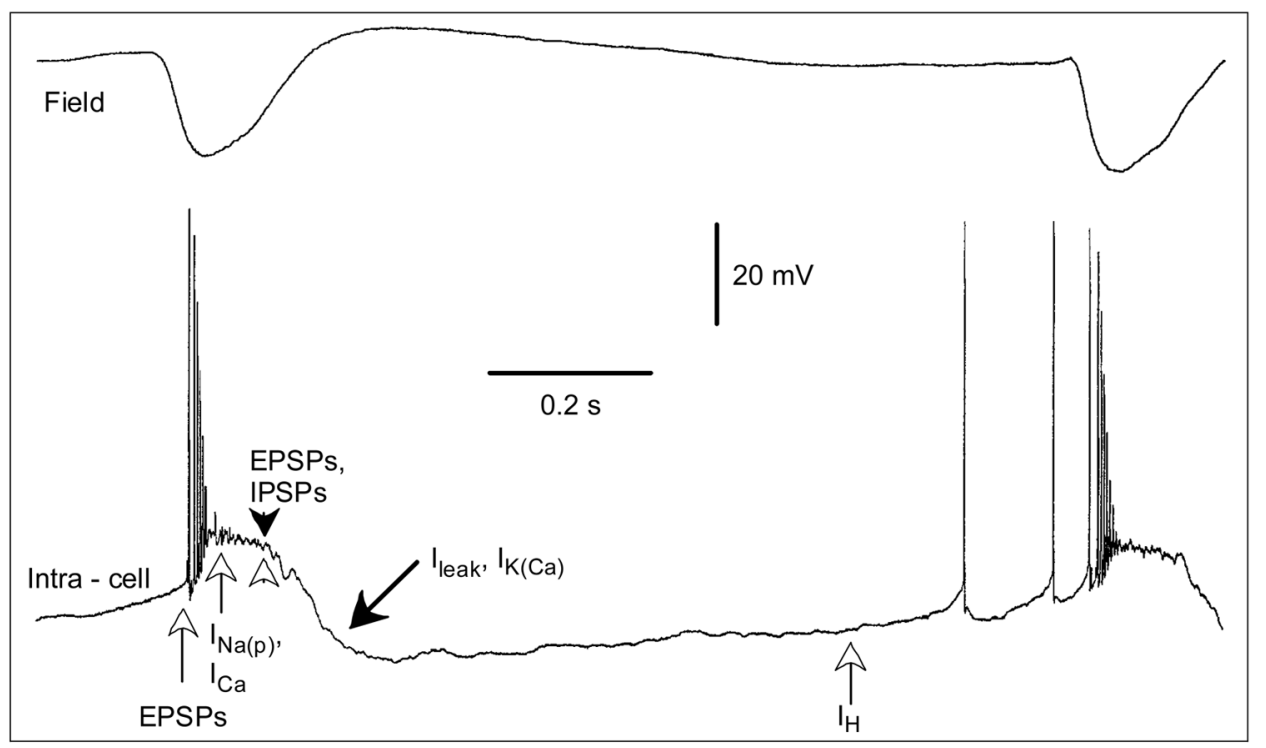

Fig. 3. Tentative representation of different synaptic and intrinsic currents activated in neocortical neurons during paroxysmal activity

See text for description of how these currents interact during paroxysmal activity. Modified from (Timofeev and Steriade 2004). 


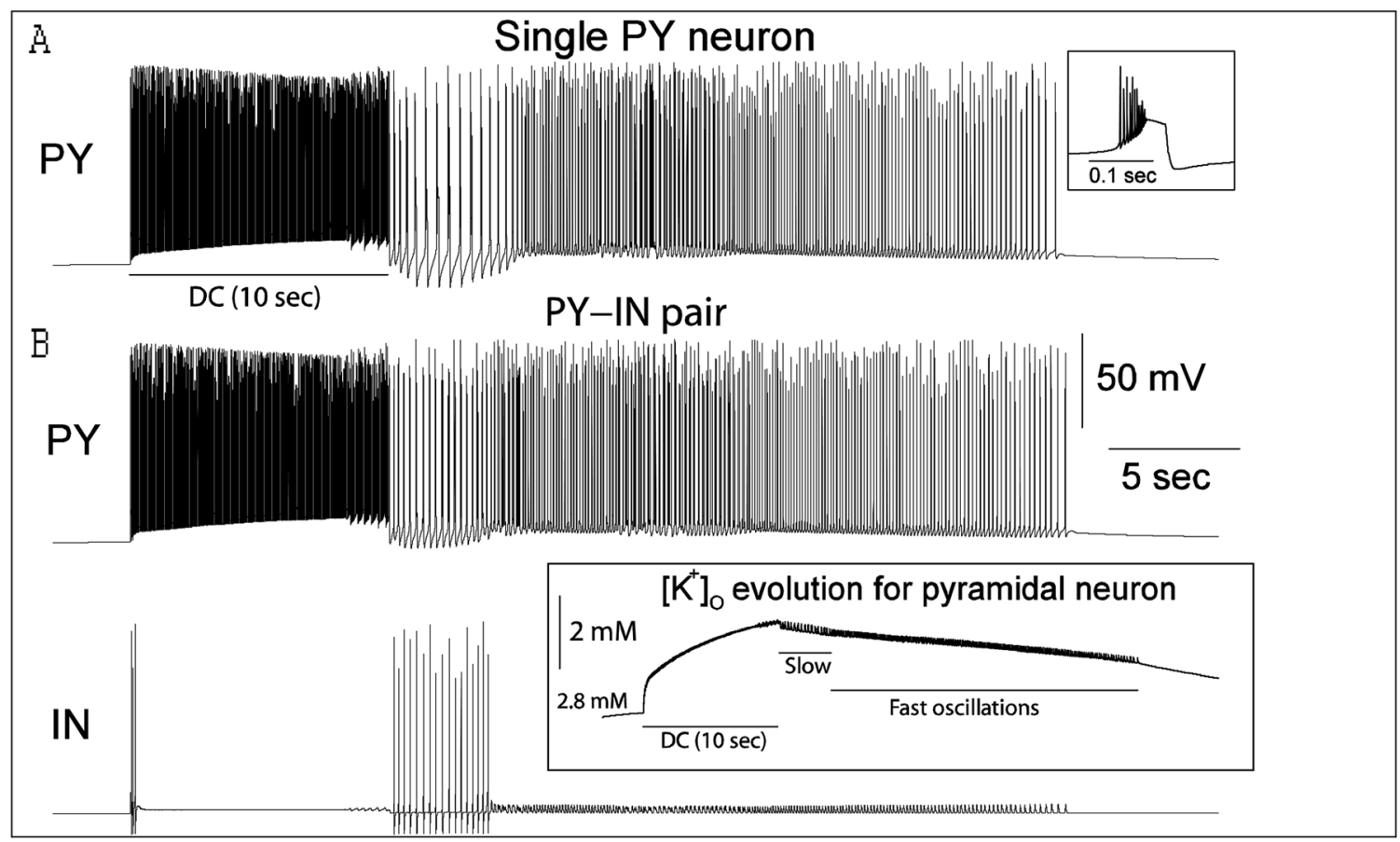

Fig. 4. Oscillatory activity mediated by elevated $\left[\mathrm{K}^{+}\right]_{\mathrm{o}}$

DC pulse (10 sec in duration, bar) was applied to the silent PY cell. Following high frequency firing, $\left[\mathrm{K}^{+}\right]_{\mathrm{O}}$ increased and maintained oscillations in PY neuron after DC pulse was removed. (A) Single PY neuron. Insert shows typical burst of spikes. (B) Reciprocally connected PYIN pair. Insert shows $\left[\mathrm{K}^{+}\right]_{\mathrm{o}}$ evolution for PY neuron. Change of the $\left[\mathrm{K}^{+}\right]_{\mathrm{o}}$ induced transition from slow $(2-3 \mathrm{~Hz})$ to fast $(10-15 \mathrm{~Hz})$ oscillations. Bursts of spikes (but not tonic spiking) in PY neuron induced spikes in the interneuron (see IN panel). 
$\mathbf{A}$

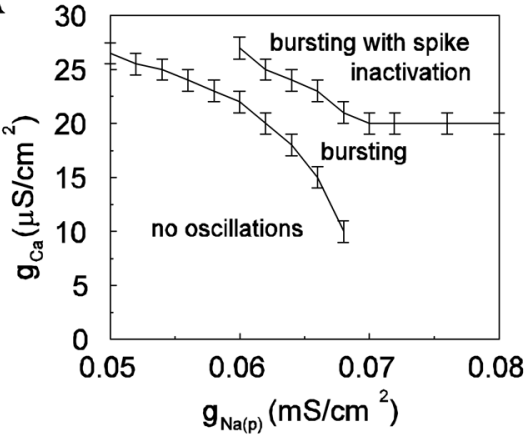

$\mathbf{B}$
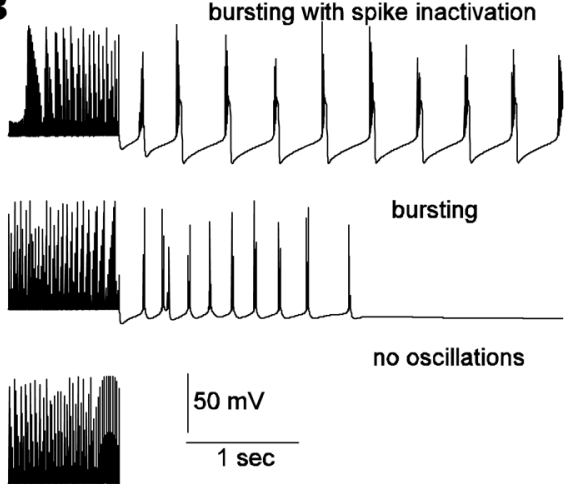

no oscillations

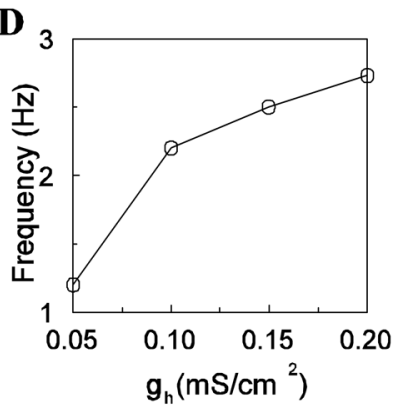

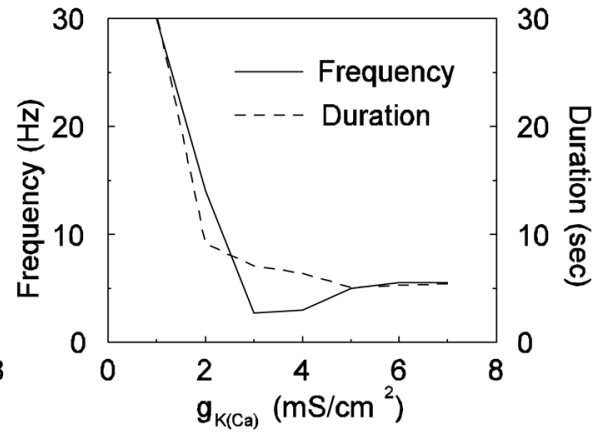

C
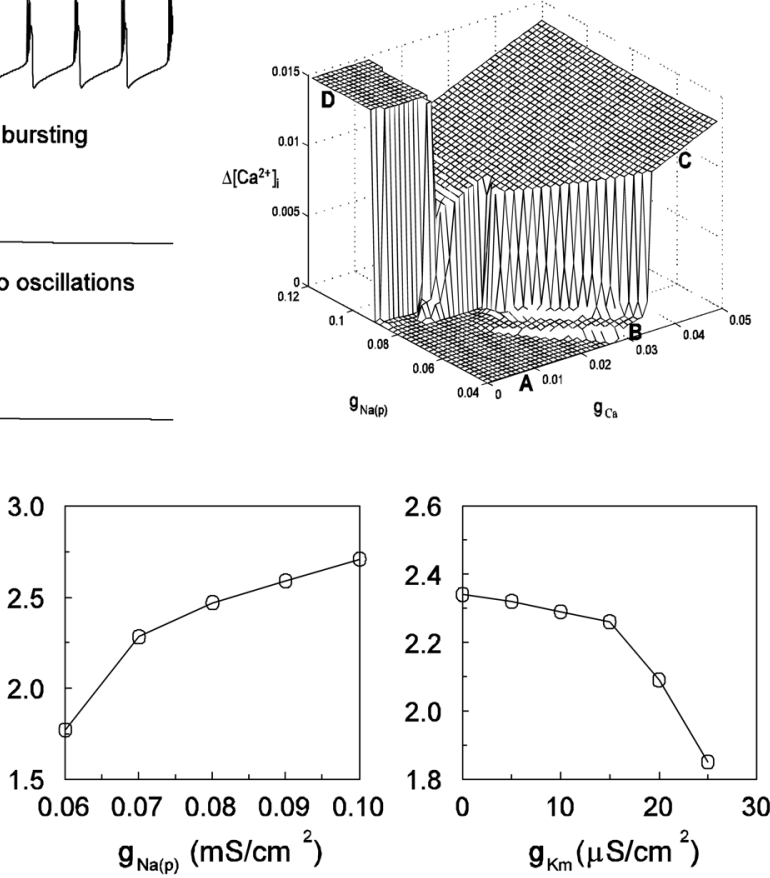

Fig. 5. Effect of intrinsic conductances on neuronal oscillations

(A) Increase of $\left[\mathrm{K}^{+}\right]_{\mathrm{o}}$ during DC stimulation led to oscillations. Sufficiently high levels of persistent $\mathrm{Na}^{+}$and high-threshold $\mathrm{Ca}^{2+}$ conductances were required to maintain periodic bursting (top left). Increase of $\mathrm{Ca}^{2+}$-dependent $\mathrm{K}^{+}$current reduced both duration and frequency of oscillations (top right). (B) Examples of PY oscillations corresponding to different regimes indicated in panel $\mathrm{A}$, left. $(\mathrm{C})\left[\mathrm{Ca}^{2+}\right]_{\mathrm{i}}$ increase during a burst as a function of parameters $\mathrm{g}_{\mathrm{Na}(\mathrm{p})}$ and $\mathrm{g}_{\mathrm{Ca}}$ for a cell held at a constant level of $\left[\mathrm{K}^{+}\right]_{\mathrm{O}}(5.5 \mathrm{mM})$. Longer bursts (more spikes or spike inactivation) produced higher $\left[\mathrm{Ca}^{2+}\right]_{\mathrm{i}}$ change. Four different regions can be discerned: $\mathrm{A}$ - no oscillations; $\mathrm{B}$ - bursting; $\mathrm{C}$ - bursting with spike inactivation; $\mathrm{D}$ - membrane potential "locked" in depolarized state. (D) Effect of the intrinsic conductances on frequency of oscillations. The most significant frequency changes (1 to $3 \mathrm{~Hz}$ ) occurred with variations of the $\mathrm{I}_{\mathrm{h}}$ maximal conductance. (Modified from (Bazhenov et al. 2004)). 


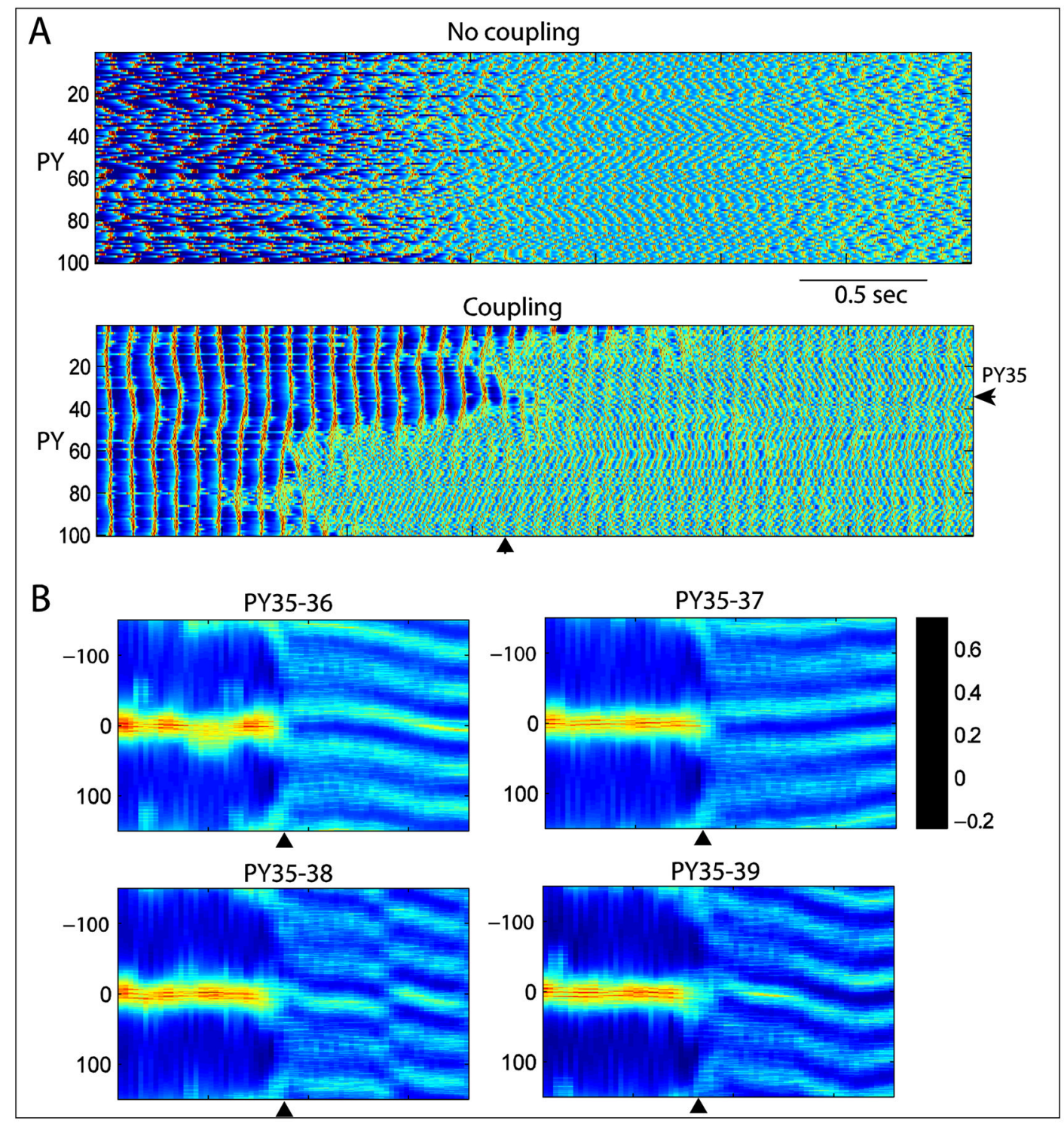

Fig. 6. Oscillations following DC stimulation in network (100 PY - 25 IN) model (A) Top, no synaptic coupling. Bottom, coupled network. (B) Time-dependent crosscorrelations between one PY neuron (PY35) and its neighbors (PY36-PY39). Without synaptic coupling all PY neurons fired independently. Including excitatory/inhibitory connections synchronized the slow oscillations. During fast run, however, PY neurons remained desynchronized. Oscillations in the neighboring PY cells displayed phase shift (local activity propagation) with sudden phase changes. (Modified from (Boucetta et al. 2008)) 


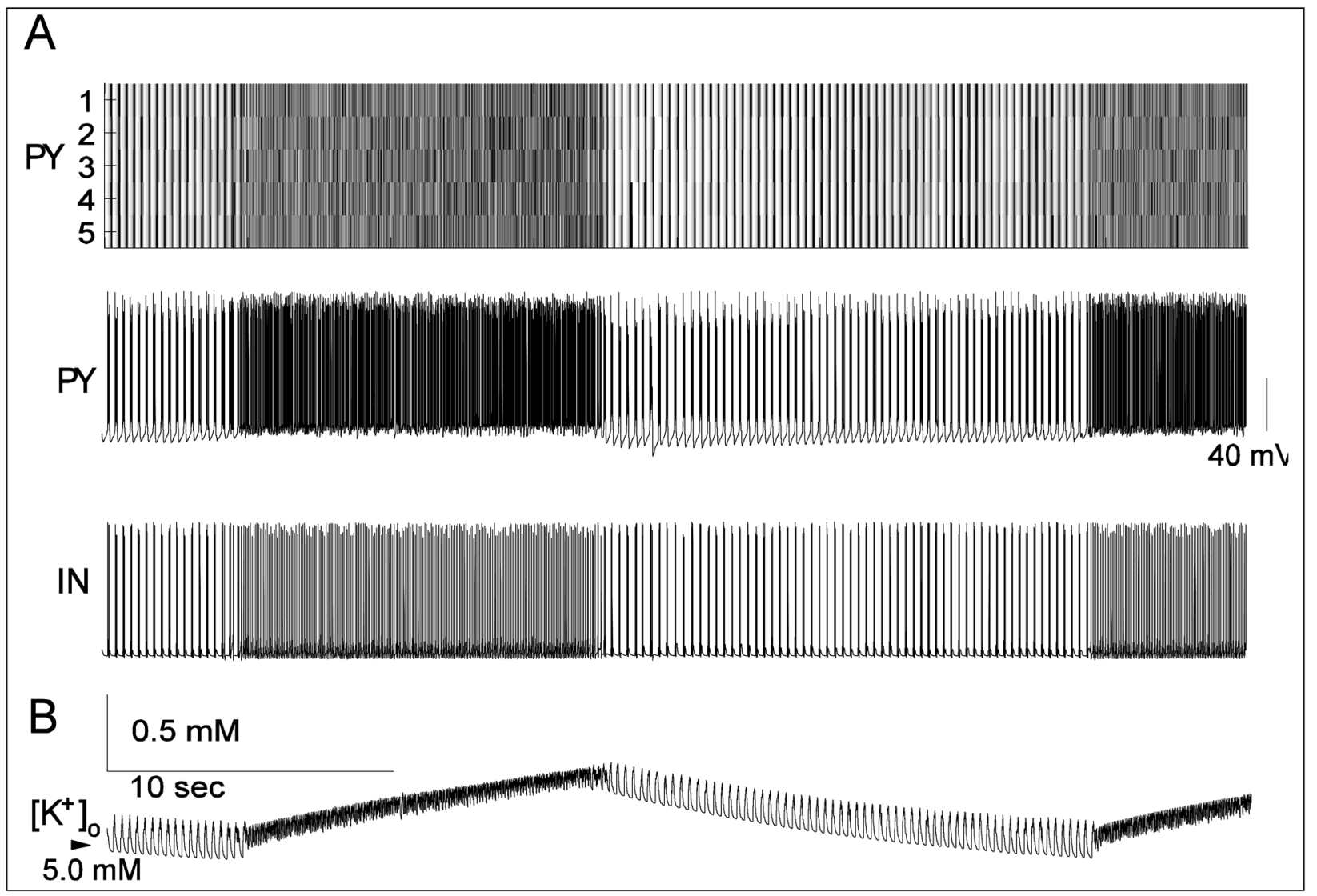

Fig. 7. Self-sustained oscillations in globally connected network with five PY cells and one IN (A) Top, network activity of PY cells (40 seconds duration) shows alternating epochs of fast run and slow bursting. Bottom, membrane voltage time course of PY cell and of IN. (B) $\left[\mathrm{K}^{+}\right]_{\mathrm{O}}$ increased during fast run and decreased during slow bursting. Upper switching point for transition from fast run to slow bursting and lower switching point for transition from slow bursting to fast run correspond to the end points of the hysteresis region. From (Frohlich et al. 2006), with permission. Copyright 2006 Society for Neuroscience. 


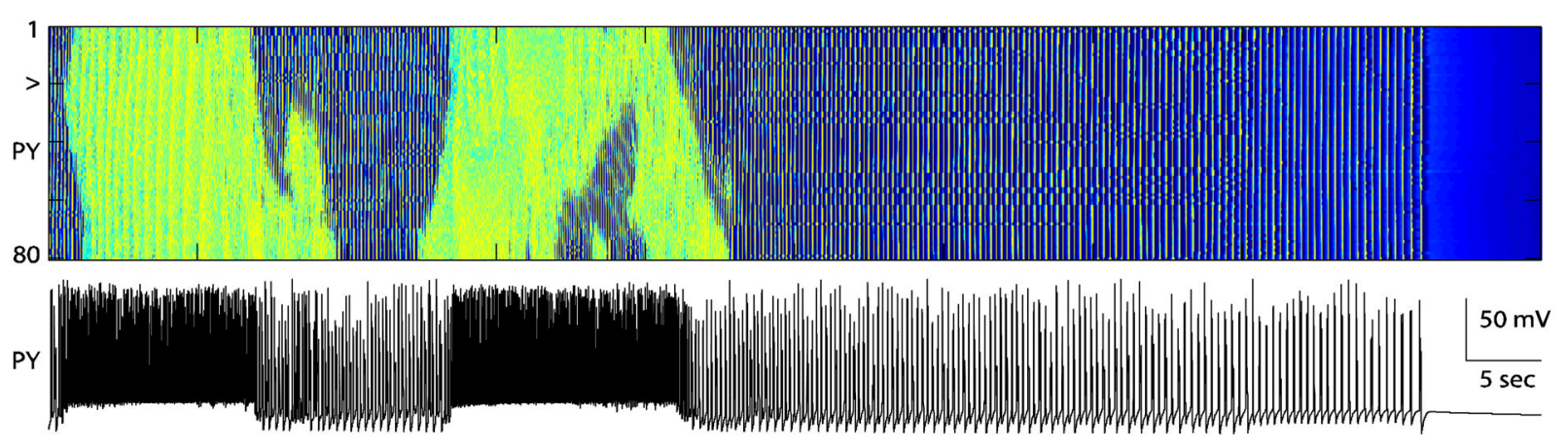

Fig. 8. $\left[\mathrm{K}^{+}\right]_{\mathrm{o}}$ controls transitions between fast runs and slow bursting

Computational model showing hysteresis between regimes of fast and slow oscillations as a function of $\left[\mathrm{K}^{+}\right]_{\mathrm{o}}$, leading to spatial patterning of slow bursting and fast runs in a cortical network model of 80 PYs and 16 INs. Transient increase in initial $\left[\mathrm{K}^{+}\right]_{\mathrm{O}}$ triggered oscillations in network which was previously silent. Activity-dependent increase in intracellular chloride concentration caused shift in balance between synaptic excitation and inhibition resulting termination of oscillatory activity. Top, network activity; bottom, membrane voltage of representative PY neuron (PY\#20). 